\title{
Effectiveness of reception class teachers' pedagogical approaches in delivering pre-primary curriculum - Evidence from practice
}

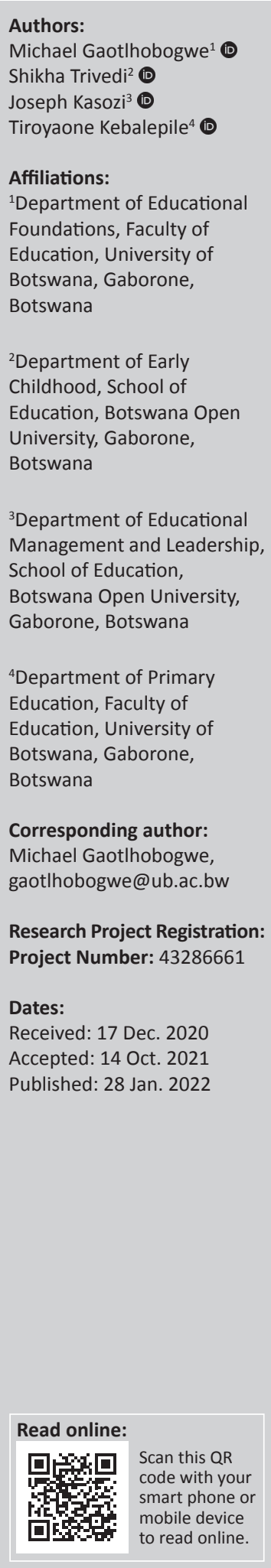

Background: This report is part of a study commissioned to provide evidence to inform quality improvements, and the rolling out of the public reception class programme (RCP) to all public primary schools in Botswana by 2020. The study adopted the Discrepancy Evaluation Model (DEM) as a theoretical framework.

Aim: One of the specific objectives of the study was to determine the effectiveness of the programme in terms of the RCP curriculum coverage and the teachers' effectiveness in delivering the curriculum. The aim of the study reported in this article was therefore to determine the reception class teachers' pedagogical approaches in delivering the RCP curriculum.

Setting: The study was conducted in Botswana where early childhood care and education was provided by private providers until 2014 when the government of Botswana introduced the RCP in public primary schools.

Methods: The study utilised a multi-method design. Stratified random sampling was used to select $10 \%$ of the 539 public primary schools that had implemented the programme since 2014 when it was introduced. An analysis tool based on the revised Bloom's Taxonomy was used to analyse the content, as well as the level of coverage of important skills within the RCP curriculum. Questionnaires were used to gather information from teachers. Interviews were used to gather information from principal education officers (PEOs) who are part of the inspectorate. Feedback received from these participants was considered as indicating performance, according to the DEM. This performance was then compared with standards (with the RCP curriculum) to determine if any discrepancies existed.

Results: Findings indicated that the RCP curriculum was adequate in coverage of skills at various levels of knowledge, understanding and appreciation. However, in some learning areas, certain competencies and performance targets were pitched at higher-order thinking. This resulted in most teachers focusing on achieving performance targets instead of following performance indicators to develop particular skills. As a result, learners demonstrated achievement of performance targets yet their developmental process skills were not fully accomplished.

Conclusion: The RCP generally had a sound teaching cadre which would generate a considerable impact on the programme, should their pedagogical approaches not be derailed by the desire to fulfil performance targets at the expense of developmental process skills.

Keywords: reception class; curriculum; pedagogical approaches; early childhood care and education; Botswana.

\section{Introduction}

Building on the recommendations of the Revised National Policy on Education (RNPE) of 1994 (Republic of Botswana 1994), a much more robust and comprehensive early childhood development and education roadmap was developed into the Early Childhood Care and Education (ECCE) Policy of 2001 (Republic of Botswana 2001). The later policy harmonised all early childhood care and development activities and delineated ages $0-2 \frac{1}{2}$ for day care, $2 \frac{1}{2}-4$ for day-care/nursery and 4-6 for pre-primary development. According to the policy, there were minimum standards to be met for all aspects of delivery. A curriculum for pre-primary was developed by the Ministry of

How to cite this article: Gaotlhobogwe, M., Trivedi, S., Kasozi, J. \& Kebalepile, T., 2022, 'Effectiveness of reception class teachers' pedagogical approaches in delivering pre-primary curriculum - Evidence from practice', South African Journal of Childhood Education 12(1), a967. https://doi.org/10.4102/sajce.v12i1.967

Copyright: (C 2022. The Authors. Licensee: AOSIS. This work is licensed under the Creative Commons Attribution License. 
Basic Education (MOBE) based on the set developmental needs and learning principles. The ECCE teachers' training is provided in various colleges of education and universities in Botswana.

The latest policy reform initiative is the Education and Training Sector Strategic Plan (ETSSP) of 2015 (Republic of Botswana 2015), which was developed with the key policy goal to generally, '... improve access, quality, inclusion and equity, accountability and governance in the education system' (p. 7). Recognising the limited supply of teachers for ECCE, the policy amongst others aimed at developing professionals in ECCE.

Effective teaching and learning in reception class is a major concern world-wide as it forms a fundamental basis for longlife learning. Effective teaching and learning at this stage can be achieved if teachers distinguished themselves and act as role models (Lacina \& Block 2011). Teachers need to focus on pedagogical practices so that learners can have knowledge as well as skills which are recognised globally. The challenge for the teachers is not only to identify and develop certain instructional strategies, but also to mould children's behaviours that are accepted as effective practices in society. The teacher has to match the instructional strategies and behaviours at the appropriate time, for individual children to achieve desired learning outcomes (Hunt, Touzel \& Wiseman 2009).

The National Development Plan 10 (Republic of Botswana 2015) envisaged rolling out the reception class programme (RCP) to $40 \%$ of the children during the plan period (20102016). The purpose of this evaluation study was to amongst others provide evidence to inform quality improvements and the rolling out of the programme to all public primary schools by 2020 . One of the specific objectives for the study was to determine the effectiveness of the programme, therefore this article reports on the findings related to this objective.

\section{Theoretical framework}

This study relied on the Provus' Discrepancy Evaluation Model (DEM) (Provus 1969) as its theoretical framework (see Figure 1). According to DEM, every evaluation stage should involve comparing (C) standards (S) with performance (P) to determine if there is a discrepancy (D). Should any discrepancy be found, that would then mean that either the standards or the performance be modified (M). The outcome of comparing $(\mathrm{C})$ standards $(\mathrm{S})$ with performance $(\mathrm{P})$ leads to either one of the following three decisions:

1. To either go to the next stage, or

2. Recycle $(\mathrm{R})$ the stage after there has been a change in the programmes standards and/or performance or

3. Terminate $(\mathrm{T})$ the programme.

In the case of this study, the DEM was adapted to align with the objective of the study, the standard was determined from the curriculum and the performance was determined by observed actions of the learners and the teachers, as well as from data gathered from teachers and principal education officers (PEOs). As a result, this article reports on findings of the study during the first stage of the evaluation process as per the DEM.

\section{Methodology}

A multi-method design was adopted to determine the effectiveness of the programme. Multi-method design allowed the use of both quantitative and qualitative approaches for aspects of the study that required different methodological approaches. Having identified schools and populations covering all the 10 regions across Botswana, samples were drawn and data were collected using document analysis, questionnaires, interviews and observations. Data collection tools included a document analysis tool, an observation check list and a questionnaire.

\section{Sampling}

Reception classes were sampled from the 539 public primary schools. Stratified random sampling was used to select $10 \%$ of the primary schools that had implemented the RCP in 2014 in each of the 10 regions across the country. It is important to note that amongst the 10 regions, there were variations in terms of numbers, location and size of the schools as well as size of the districts. These variations resulted in differences in the implementation of the RCP as well as differences in the number of schools sampled. The sampling, therefore, considered these variations, for example, the location of the schools whether urban, peri-urban, rural or remote.

The sample included a total of 61 schools from which 79 reception class teachers and their pupils were used as participants. Of the 79 RCP teachers, six (6) were male and 73 were female. Most of these RCP teachers were aged between 21 and 31 and 32 and 41 with $42 \%$ and $39 \%$ of them in each of

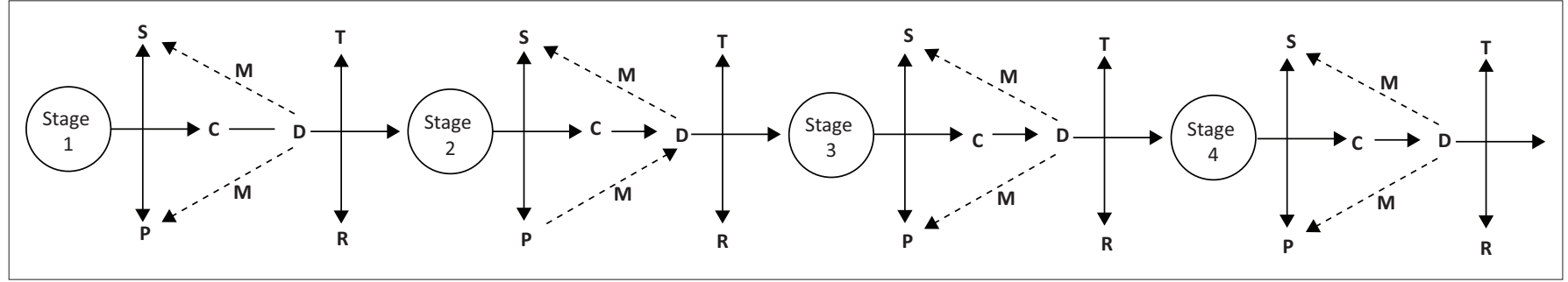

$\mathrm{S}=$ Standard P = Performance; $\mathrm{C}=$ Compare; $\mathrm{M}=$ Modify $\mathrm{D}=$ Discrepancy $\mathrm{T}$ = Terminate; $\mathrm{R}=$ Recycle

FIGURE 1: Provus' Discrepancy Evaluation Model. 
these age ranges, respectively. A total of $79 \%$ had diplomas whilst $12 \%$ and $9 \%$ had certificates and degrees, respectively. According to government of Botswana policy, those holding certificates work as teacher aides. Thirteen PEOs were also interviewed, whilst all the 79 RCP teachers completed a questionnaire.

\section{Data collection}

In assessing the adequacy of the curriculum to determine standards as defined in the DEM (Stage 1), data were acquired from different sources using different instruments as alluded above. An analysis tool based on the revised Bloom's taxonomy, which is a classification of thinking organised by levels of complexity, was used to analyse the content of the RCP curriculum. The tool was used to check the availability and level of coverage of important skills such as: pre-reading, pre-writing, communication, mathematical and scientific thinking, socio-emotional development, creativity and self-help.

\section{Reception class teacher questionnaire}

Teacher questionnaire (see Appendix 1) was used to gather biographical data from the teachers, such as age, gender and qualification. Other attributes assessed included: selfefficacy regarding curriculum completion, teaching and learning, attitudes to the profession, attitudes to learners and collaboration with other teachers. Teacher perceptions about the infrastructure and resources were elicited through the questionnaire as well. Information gathered from teachers and other participants was then considered as performance of the programme, according to the DEM, which is compared with standards to determine the existence of any discrepancies.

\section{Principal education officers interview protocol}

From each region, PEOs were interviewed using the interview protocol presented in Appendix 2. These PEOs are part of the inspectorate whose responsibility is to monitor, guide and provide mentorship in the programme. As officers-in-charge, they provided data on the efficiency, adequacy of delivery and adequacy of the management systems including standards monitoring and quality assurance systems.

\section{Classroom observation tool}

Classroom observation tool (see Appendix 3) was used to assess teachers' behaviour relative to reception class instruction practice. The tool was also used to record teacherlearner, learner-teacher and learner-learner interactions. All these aspects represented performance as defined in the DEM. A team of seven researchers working with research assistants was deployed to conduct classroom observations across the selected schools. The observations were conducted over a period of one month during classroom activities as well as play activities.

\section{Data analysis}

Data analysis procedures were selected based on their suitability in addressing the objectives of the evaluation. The RCP curriculum document (standards) was analysed to examine the extent to which the implementation of the RCP (performance) was aligned to educational policies (standards). In addition, the RCP programme and project implementation and operational documents were used to determine (compare) whether the programme was on track, delayed or behind schedule (performance). Qualitative data were analysed using NVIVO 12, a software that allowed the data to be contained within folders and managed through creating codes and word clouds. These codes and word clouds emerged as themes to determine frequencies and the amount to which a particular theme was made reference to. Quantitative data, in terms of teachers' qualifications and performance, were analysed using Statistical Package for the Social Sciences (SPSS version 24).

\section{Results}

Efficiency in the delivery of RCP was determined by assessing the adequacy of inputs such as the curriculum and teachers (standards). The curriculum and teacher qualifications represented the standard (S) as indicated in the theoretical framework, whilst teachers' behaviour relative to reception class instruction practice, as well as teacher/learner, learner/teacher and learner/learner interactions represented performance $(\mathrm{P})$.

The curriculum framework had six learning areas which sought to develop the knowledge and understanding of various concepts and equip children with skills for life. These six learning areas are:

1. Personal, emotional and social development.

2. Language development and early literacy.

3. Health, nutrition and safety.

4. Mathematical and scientific thinking.

5. Physical, creative and aesthetic development and

6. Moral and spiritual guidance.

Each learning area has expected outcomes (performance targets) with performance indicators to track children's progress.

Findings revealed that the RCP curriculum was adequate in coverage of skills at various levels of knowledge, understanding and appreciation. However, in some learning areas such as language development and early literacy and mathematical and scientific thinking, some competencies and expected outcomes (performance targets) were pitched at higher order thinking (application and analysis) which resulted in most teachers focusing to achieve expected outcomes (performance targets) instead of following the performance indicators to develop particular skills. Another example under pre-reading (book knowledge and appreciation), one of the expected outcomes (performance target), is to demonstrate interest and knowledge of book details, and the performance indicator is arranging books on shelves by content and authors, which 
requires a high order thinking skill. Similarly, recognition of three letter words, and demonstrate ability to read and correctly spell simple words, ability to copy and write recognisable letters and short words, recognise and use commas, full stops and question marks are skills that need high order thinking. This resulted in some of the skills (prewriting) not properly developed, even though the children could demonstrate the expected outcome (performance target). For example, most children were able to write but could not hold the pencil properly or follow the right sitting posture.

In mathematical and scientific thinking, some of the expected outcomes (performance targets) were: ability to group various objects according to at least two attributes, demonstrate ability to perform analogical thinking tasks, count objects in groups from two to tens, compare measurement with reference to weight and capacity, add and subtract numbers that have answers less than 10, which requires high level thinking skill.

The lack of coverage of skills and competencies at introductory or foundation level was also captured in interviews with education officers from different regions. One education officer commented that:

'When I move around schools, I realize that kids are not trained on fine motor skills and socializing, how to walk, how to do this and that rather on reading and writing, basically, RC should be a foundation of everything but now kids are being damaged by being made to read and write. When they get to higher standard now teachers find it hard to take them through the 6 weeks breakthrough programme since now kids have covered everything at RC ... Parents also put teachers on pressure. They go there excited "hay my child can read, my child can count'. (Male, Principal Education Officer)

A similar comment was made by another education officer in another region, the officer commented that:

'Learners should be given pre reading, pre writing activities. At the same time they should be given time to play. They should not be taught as if they were in the primary school classroom ... In some schools e.g. in (Name of school withheld) the learners were writing as if they were in standard 3. It seems the Deputy School head advised teachers to teach.' (Male, Principal Education Officer)

Overall, there were five references made during interviews with education officers which indicated that because of pressure from parents and supervisors, teachers were pitching the level of the RCP syllabus coverage higher than the expected level of 4-5 year olds.

Teachers' views also indicated that the RCP curriculum was adequate. Almost all of them agreed or strongly agreed with statements about the adequacy of the RCP curriculum.

\section{Teacher qualifications}

Teachers' qualification was another variable that was assessed to determine standards $(\mathrm{S})$ and performance $(\mathrm{P})$ in the delivery of the curriculum. The results shown in Figure 2 indicate that teachers handling $\mathrm{RC}$ were qualified with at least a diploma. Kweneng, Chobe and Gantsi regions had $100 \%$ qualified teachers with diploma in early childhood education followed by North West and South regions at $88.9 \%$ and $87.5 \%$, respectively, and Central, Kgatleng, North East, South East and Kgalagadi regions at 77.8\%, 75.0\%, $66.7 \%, 57.1$ and $42.9 \%$, respectively. Regions that did not operate at $100 \%$ diploma level qualifications had teachers qualified at certificate and degree levels in early childhood education. It is also evident from Figure 2 that the South East region had the highest number of teachers with degrees in early childhood education. These results are a clear indication that RCP teachers were qualified to handle the RCP curriculum and therefore meeting the standard required.

Outputs, outcomes and impact were also assessed to determine performance $(\mathrm{P})$ to be compared with standards of RCP. These outputs included performance of teachers as well as learner outcomes (level of school readiness), especially in terms of emerging literacy and numeracy skills. These were evaluated using different instruments as indicated in the methodology section.

Teacher's performance was also assessed through their responses to statements as shown in Table 1. Findings indicated that $87.3 \%$ of $R C$ teachers either agreed or strongly agreed that they were able to complete the RC syllabus within the 1 year allocated for the programme. That showed that RC teachers' performance in terms of programme delivery was compared very well with standards. Teachers' performance was further verified with their effective use of instructions, which make learners adapt to the school curriculum and communicate with teachers freely. According to the RC teachers, a majority of them either agreed or strongly agreed that they were well trained to handle reception class learners, that learners were free to communicate with them and that learners were adapting well to the school curriculum. This was an indication of the effectiveness of the teachers and the programme resulting in positive outputs,

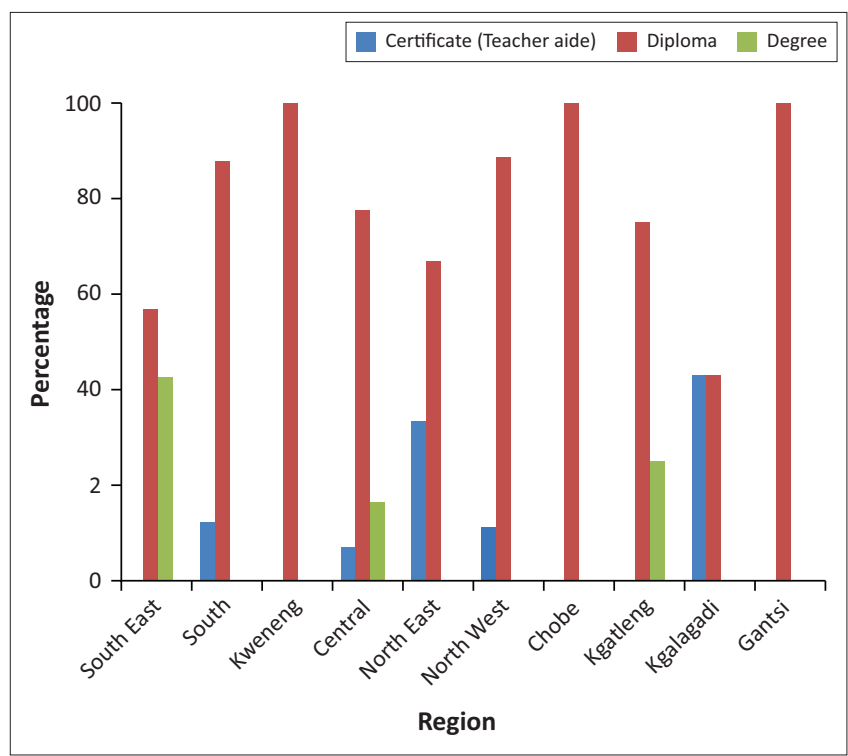

FIGURE 2: Reception class teachers' qualifications by region. 
outcomes and impact. Even though $83.7 \%$ of the teachers agreed or strongly agreed that they were able to complete the reception class syllabus within the 1 year allocated for the programme, there was evidence that some, though not many, may be struggling. Linked to this was a concern that was raised during an interview with a PEO who commented that:

'For the past 3 or 4 months we have a school (name withheld), and it has approached us telling us that we are employing the wrong people into this reception class, they are questioning their certificates, that most people whom we have employed have graduated online through some Institution (name withheld). They were alleging that some of their courses took 3 to 6 months ...' (Male, Principal Education Officer)

If indeed there were institutions or an institution that churns out graduates who were not well-trained, the effectiveness of the programme in terms of output, outcomes and impact would be affected negatively.

Finally, learner outcomes were assessed in terms of developmental process skills. The psychological, social and intellectual development of the learners manifested in skills that the they acquired by attending the RCP. Some of these skills were cognitive such as emerging literacy and numeracy, whilst some included: moral, social, emotional and physical skills. The programme's ability to provide opportunities for children to be creative and innovative, to think critically, solve problems and make decisions as well as the ability to learn and work alone or with others was also assessed to determine the effectiveness of the programme. School heads and teachers completed questionnaires relating to the extent to which learners acquired skills intended for in the RCP. The PEOs were interviewed to share their views concerning development of these skills.

Reception class teachers were asked to indicate their views on whether learners acquired the same skills that the school heads responded to concerning their adequacy and degree of coverage. As shown in Table 2, greater proportions of RCP teachers agreed that the learners who attended the RCP acquired the skills. When proportions of RCP teachers who Agreed and those who Strongly Agreed were added, the proportions ranged from $95 \%$ to $99 \%$. In this section, teachers' proportions for Agree and Strongly Agree were added and presented. Teachers perceived the learners to have acquired numeracy skills with total proportions of $99 \%$ Strongly Agreeing and Agreeing. For the acquisition of literacy skills, again 99\% of the teachers either Agreed or Strongly Agreed. According to $98 \%$ of the teachers, learners had acquired communication skills and large and fine motor skills. There were also a majority of the teachers who supported the statements that learners had attained socio emotional skills, creative and problem-solving skills and self-help skills with percentages of $96 \%, 95 \%$ and $98 \%$, respectively.

\section{Discussions and conclusion}

\section{Teacher performance}

The evaluation of teachers' performance was ascertained from observations, and responses to a questionnaire by the
TABLE 1: Reception class teachers' responses to statements on their performance.

\begin{tabular}{|c|c|c|c|c|}
\hline Statements on RC teachers' performance & SA & A & D & SD \\
\hline $\begin{array}{l}\text { I am able to complete the reception class syllabus in } \\
\text { one year }\end{array}$ & 36.7 & 50.6 & 8.9 & 3.8 \\
\hline I am well trained to handle reception class learners & 74.7 & 20.3 & 1.3 & 2.5 \\
\hline Learners are free to communicate with me & 75.9 & 22.8 & 0 & 1.3 \\
\hline $\begin{array}{l}\text { The time allocated for the completion of the } \\
\text { Reception class syllabus is adequate }\end{array}$ & 19.0 & 58.2 & 13.9 & 5.1 \\
\hline Learners are adapting to the school curriculum & 45.6 & 46.8 & 0 & 1.4 \\
\hline
\end{tabular}

$\mathrm{RC}$, reception class; SA, Strongly Agree; A, Agree; D, Disagree; SD, Strongly Disagree.

TABLE 2: Reception class programme teachers' responses on the effectiveness of the reception class programme on learners.

\begin{tabular}{lcccc}
\hline $\begin{array}{l}\text { Statements relating to coverage of the RCP } \\
\text { curriculum on pre-learning skills }\end{array}$ & SA & A & D & SD \\
\hline Learners from RCP have emerging literacy skills & 49.4 & 39.2 & 1.1 & 1.5 \\
Learners from RCP have numeracy skills & 67.1 & 31.6 & 0 & 1.3 \\
Learners from RCP have communication skills & 64.6 & 32.9 & 1.3 & 1.3 \\
Learners from RCP have large and fine motor skills & 72.2 & 25.3 & 1.3 & 1.3 \\
Learners from RCP have socio emotional skills & 57.0 & 39.2 & 1.3 & 2.5 \\
Learners from RCP have creative and problem & 46.8 & 48.1 & 2.5 & 1.3 \\
solving skills & & & & \\
Learners from RCP have self-help skills & 57.0 & 38.0 & 2.5 & 1.3 \\
\hline
\end{tabular}

RCP, reception class programme; SA, Strongly Agree; A, Agree; D, Disagree; SD, Strongly Disagree.

teachers themselves. Teachers, in general, evaluated themselves as competent and as able to finish the curriculum on time. However, the classroom observations indicated that in an effort to finish the curriculum, some teachers were not following the developmentally appropriate approaches. This was confirmed from the feedback received from the PEOs, that most of the teachers looked at the learning outcomes and used any approach to fulfil the learning outcomes, instead of following developmentally appropriate learning approaches. It was concluded that RC teachers were capable of completing the syllabus, thereby assisting learners to grasp various social, psychomotor and cognitive skills. Teachers were also able to assist learners to be creative and innovative, think critically, solve problems and make decisions as well as being able to learn and work alone or with others.

When coupled with the finding that most teachers were qualified (with certificates, diploma and bachelor's degrees in early childhood), it was not surprising that their overall performance was mostly above average. This assertion linked quality early learning and development to the educational qualifications of teachers. The most effective preschool teachers - those with at least a 4-year college degree and specialised training in early childhood - have more responsive interactions with children, provide richer language and cognitive experiences and are less authoritarian.

Findings indicated that teachers in the RCP were performing relatively up to expectations. More than $80 \%$ of the teachers held a diploma in ECE. There was concern from very few respondents who felt that ECE teacher qualifications from some of the training initiations were not up to standard because the training duration was 6 months. Self-reports from the teachers indicated that the teachers believed that they were competent enough to teach in the RCP. The fact that teacher performance was deemed to be satisfactory 
meant that the RCP had a strong teaching force that could be relied on to deliver the RCP effectively in the future. The teachers should be able to learn more ECE skills as they are exposed to more professional development initiatives.

\section{Learner performance}

It was noted that learners acquired the key skills. The acquisition of these skills would certainly empower learners with their learning, post the RCP. Hopefully, there would be noticeable improved performance in the future amongst Batswana learners in reading, mathematics and other subjects. Future results from learners from Botswana in local and international assessments like The Southern and Eastern Africa Consortium for Monitoring Educational quality (SACMEQ), Trends in International Mathematics and Science Study (TIMSS) and Progress in International Reading Literacy Study (PiRLS) should be expected to show much improvement from the current and past results. Lack of pre-primary learning was identified as a major factor for low results attained by learners from Botswana in international comparative reports. However, observations recorded numerous instances where pupils did not apply correct processes that lead to attainment of performance indicators. On the other hand, teachers were not bothered to check if pupils were developmentally on track in terms of processes leading to attainment of these performance targets. In most cases, these pupils were treated like little adults and told to sit still, without teachers noticing that pupils were fidgeting because of fatigue as a result of their sitting posture.

The RCP generally had a sound teaching cadre which would generate considerable impact on the programme, should their pedagogical approaches not be derailed by the desire to fulfil performance targets at the expense of developmental process skills. The RCP curriculum would be effectively delivered and learner outcomes would be stronger.

\section{Recommendations}

The following recommendations were made to address the issues that have been identified under the specific objective of this study. One amongst them is to determine the effectiveness of the programme:

- The RC teachers should adopt learning through play as the major pedagogical approach used in the development of skills and competencies from the curriculum framework.

- The RC teachers should pay particular attention to processes leading to acquisition of skills and competencies as opposed to focusing more on performance targets.

- The MOBE should collaborate with training institutions to ensure that ECCE graduates are appropriately trained to adopt pedagogical approaches relevant to learners aged 2 to 5 years old

\section{Acknowledgements}

The authors wish to acknowledge Botswana Educational Research Association (BERA) for the project administration support provided throughout the research project. Authors also acknowledge the role played by the schools, school heads, teachers, pupils and officers who participated in the project.

\section{Competing interests}

The authors declare that they have no financial or personal relationships that may have inappropriately influenced them in writing this article.

\section{Authors' contributions}

M.G. conceived and planned the experiments and methodology, and also provided the much needed supervision of the team. Authors M.G., S.T., J.K. and T.K. developed research instruments and were all involved in data collection. M.G. contributed to data analysis and interpretation of results. M.G. took the lead in writing the manuscript. All authors provided critical feedback and helped in shaping the research, analysis and manuscript review.

\section{Ethical considerations}

A research permit was acquired from the Ministry of Basic Education in Botswana. Permission was also acquired from all the regional education offices and selected school heads where the research was conducted. The project had a technical reference team consisting of experts from stakeholders. This team approved the study protocols and provided guidelines for study procedures.

\section{Funding information}

The author(s) disclosed the receipt of the following financial support for the research. This work was supported by the United Nations International Children Emergency Fund in collaboration with Ministry of Basic Education, Republic of Botswana [grant number 43286661].

\section{Data availability}

The data that support the findings of this study are available with UNICEF. Restrictions apply to the availability of these data, which were used under license for this study. Data are available from BERA with the permission of UNICEF.

\section{Disclaimer}

The views and opinions expressed in this article are those of the authors and do not necessarily reflect the official policy or position of any affiliated agency of the authors, and the publisher/s.

\section{References}

Hunt, G.H., Touzel, T.J. \& Wiseman, D.G., 2009, Effective teaching: Preparation and implementation, Charles C. Thomas Publisher, Ltd, Springfield, IL.

Lacina, J. \& Block, C.C., 2011, 'What matters most in distinguished literacy teacher education programs?', Journal of Literacy Research 43(4), 319-351. https://doi. org/10.1177/1086296X11422033 
Provus, M., 1969, The discrepancy evaluation model: An approach to local program improvement and development, Office of Education (DHEW), Bureau of Research, Washington, DC. Republic of Botswana, 1994, The Revised National Policy on Education, Government
Press, Gaborone.
Republic of Botswana, 2001, Early Childhood Care and Education Policy, Ministry of Education, Gaborone.

Republic of Botswana, 2015, Education and training strategic sector plan (2015-2020), Ministry of Education and Skills Development, Gaborone.

Appendices starts on the next page $\rightarrow$ 


\section{APPENDIX 1: Reception class teachers questionnaire}

It is with much appreciation that you have taken the time to answer this questionnaire. With utmost assurance, all the information acquired is strictly confidential. It is necessary that you answer the questions as honestly as you can.

Please complete the questionnaire in relation to your reception classes by placing a tick $(\mathrm{V})$ in the appropriate box.

\section{SECTION A}

\section{BIOGRAPHICAL INFORMATION}

\begin{tabular}{|l|l|}
\hline Female & \\
\hline Male & \\
\hline
\end{tabular}

\begin{tabular}{|l|l|l|}
\hline Age range & $21-31$ & \\
\cline { 2 - 3 } & $32-41$ & \\
\cline { 2 - 3 } & $42-51$ & \\
\cline { 2 - 3 } & $52-$ & \\
\hline
\end{tabular}

\begin{tabular}{|l|l|l|}
\hline Qualification & Certificate & \\
\cline { 2 - 3 } & Diploma & \\
\cline { 2 - 3 } & Degree & \\
\cline { 2 - 3 } & Masters & \\
\cline { 2 - 3 } & PhD & \\
\hline
\end{tabular}

\section{SECTION B}

Statements

A

D

Learners are always happy and settled.

Learners make good progress in social interaction.

Learners are safe and secure.

Learners are adapting to the school curriculum.

The reception class programme is effective in the smooth transition of learners from reception to standard 1.

There is academic improvement from learners who have attended reception class.

The infrastructure is conducive for teaching and learning.

Reception class programme helps in de-attaching learners from the parents?

There is adequate teaching and learning resources

There are challenges of early withdrawals

I have attended the reception class programme pre-implementation workshop(s).

I am well-trained to handle reception class learners

There is regular visits for monitoring and in-service training

Food served for learners is nutritious

I enjoy teaching reception class learners

Learners are free to communicate with me

Parents are involved in reception class programme activities

Parents actively participate in reception class programme activities

Reception class programme caters for learners with disabilities

I am able to complete the reception class syllabus in 1 year

The time allocated for the completion of the reception class syllabus is adequate.

I am able to handle the number of learners in my class

Setswana is an effective language of instruction at reception class level.

English is an effective language of instruction at reception class level.

Set aims and objectives of the reception class syllabus are clear and achievable

The structure of the timetable allows for child initiated activities.

There is a provision for planned formal and informal assessment including observation.

Assessment is used to inform parents about learners' academic progress.

Assessment is used to gain information about learners' progress.

Learners from reception class programme have the following skills:

Emerging literacy

Numeracy

Communication

Large and fine motor

Socio-emotional

Creative and problem-solving

Self-help

$\mathrm{SA}=$ Strongly agree; $\mathrm{A}=$ Agree $; \mathrm{D}=$ Disagree $\mathrm{SD}=$ Strongly disagree 


\begin{tabular}{|c|c|}
\hline Boys & Girls \\
\hline & \\
\hline
\end{tabular}

\section{APPENDIX 2: Principal education officers interview guide}

It is with much appreciation that you have taken the time to sit for this interview. With utmost assurance, all the information acquired is strictly confidential. It is necessary that you answer the questions as honestly as you can:

1. What role do you play in supporting the RCP programme?

2. What are your experiences with the RCP programme?

3. How do you monitor the reception class programme in the region?

4. Are you involved in helping the schools implement and run the reception class?

5. How do you support collaborative work amongst teachers in your region? 


\section{APPENDIX 3: Reception class indoor and outdoor classroom activities observation tool}

\section{Background information}

Name of School

Class Code

Class size

District

Activity

Observed

Date and Time of

Observation

Observer

Teacher

\begin{tabular}{|c|c|c|c|}
\hline STATEMENT & YES & NO & NOTES \\
\hline Most of the activities are teacher directed & & & \\
\hline The teacher, in most cases, tells learners what to do & & & \\
\hline The teacher uses individual instruction & & & \\
\hline During group activities, most learners are not involved & & & \\
\hline The teacher is not prepared for the activities & & & \\
\hline The teacher reprimands problematic learners ( use of 'stop, no, don' $t$ ') & & & \\
\hline Learners' interactions are rarely encouraged during indoor activity & & & \\
\hline The teacher discourages learners' disruptive behaviour & & & \\
\hline The teacher reinforces learners' positive behaviour & & & \\
\hline The teacher uses transitional activities & & & \\
\hline Learners are given materials to use (toys, pencils) & & & \\
\hline The teacher uses various approaches to assist all learners & & & \\
\hline Appropriate content is given to learners & & & \\
\hline The teacher engages learners in different activities & & & \\
\hline Large and small groups are used during activities & & & \\
\hline Positive feedback is provided by the teacher & & & \\
\hline The teacher gives clear instructions to learners & & & \\
\hline The teacher supports learners who seem to be slow in learning & & & \\
\hline The teacher only gives instruction and sits back and watches learners & & & \\
\hline The teacher caters for learners of different abilities & & & \\
\hline Instruction is modified when learners show signs of misunderstanding & & & \\
\hline
\end{tabular}

Indoor/Classroom Learning Area

\begin{tabular}{|l|l|l|l|}
\hline STATEMENT & YES & NO & NOTES \\
\hline Classroom environment is welcoming and conducive & & & \\
\hline The sitting arrangement is appropriate & & & \\
\hline Various teaching stations are well-arranged & & & \\
\hline There are adequate materials for learners to use during class activities & & & \\
\hline Learners fight over toys & & & \\
\hline Space is adequate for use by learners & & & \\
\hline Learners can move freely in the classroom & & & \\
\hline Materials used for learning are appropriate to learners' ages & & & \\
\hline
\end{tabular}


The learning aids are colourful

Outdoor Learning Area

\begin{tabular}{|c|c|c|c|}
\hline STATEMENT & YES & NO & NOTES \\
\hline \multicolumn{4}{|l|}{ Outdoor environment is conducive to learning } \\
\hline \multicolumn{4}{|l|}{ Play equipment is appropriate and well-arranged } \\
\hline \multicolumn{4}{|l|}{ Equipment is safe to use by learners } \\
\hline \multicolumn{4}{|l|}{ The entire outdoor area is safe for learners } \\
\hline \multicolumn{4}{|l|}{ Learners enjoy outdoor activities } \\
\hline \multicolumn{4}{|l|}{ Space is adequate for use by learners } \\
\hline \multicolumn{4}{|l|}{ Availability of play materials that help learners to develop physically } \\
\hline \multicolumn{4}{|l|}{ Availability of play equipment that helps learners to develop intellectually } \\
\hline \multicolumn{4}{|l|}{ Availability of play equipment that enhances the social skills } \\
\hline Availability of play equipment that enhances language development & & & \\
\hline
\end{tabular}

\section{Learners}

\begin{tabular}{|c|c|c|}
\hline STATEMENT & & \\
\hline \multicolumn{3}{|c|}{ All learners are engaged in activities } \\
\hline \multicolumn{3}{|c|}{ Learners allowed to choose their own activities } \\
\hline \multicolumn{3}{|c|}{ Learners directed by the teacher to choose the activities. } \\
\hline \multicolumn{3}{|c|}{ Learners effectively use the learning materials } \\
\hline \multicolumn{3}{|l|}{ Learners interested in learning } \\
\hline \multicolumn{3}{|c|}{ Materials help learners to develop intellectually } \\
\hline \multicolumn{3}{|c|}{ As they use the learning materials, do learners develop physically? } \\
\hline \multicolumn{3}{|c|}{ Can learners respond to the teacher's instructions? } \\
\hline \multicolumn{3}{|l|}{ Do learners enjoy play activities? } \\
\hline \multicolumn{3}{|c|}{ Do activities enhance the fine motor skills? } \\
\hline \multicolumn{3}{|c|}{ Do the activities encourage learners to explore? } \\
\hline \multicolumn{3}{|c|}{ Do activities expose learners to numerical concepts? } \\
\hline \multicolumn{3}{|l|}{ Can learners sort and classify? } \\
\hline \multicolumn{3}{|c|}{ Can learners hold the writing tool? } \\
\hline \multicolumn{3}{|l|}{ Can they write? } \\
\hline \multicolumn{3}{|l|}{ Can they sing? } \\
\hline \multicolumn{3}{|l|}{ Can they read pictures? } \\
\hline \multicolumn{3}{|l|}{ Can they say their names? } \\
\hline \multicolumn{3}{|c|}{ Can they say their parents' names? } \\
\hline \multicolumn{3}{|c|}{ Can learners solve problems on their own? } \\
\hline \multicolumn{3}{|c|}{ Do activities given to learners enhance the gross motor skills? } \\
\hline Can learners climb up frames? & & \\
\hline
\end{tabular}

